\title{
Emotional problems of Infertile Egyptian women
}

\author{
Sahar M. Yakout ${ }^{* 1}$, Mona Talaat ${ }^{2}$, Elham M. Fayad ${ }^{3}$ \\ ${ }^{1}$ College of Nursing, Alexandria University, Alexandria, Egypt \\ ${ }^{2}$ College of Nursing, Cairo University, Cairo, Egypt \\ ${ }^{3}$ King Saud University, Riyadh, Saudi Arabia
}

Received: May 16, 2016

DOI: $10.5430 /$ jnep.v7n1p146

\author{
Accepted: July 31, 2016 \\ Online Published: October 16, 2016 \\ URL: http://dx.doi.org/10.5430/jnep.v7n1p146
}

\begin{abstract}
Background: Infertility is a very stressful life experience where women may experience emotional distress, threat, depression, anxiety, phobia, disappointment and marital problems. Overall prevalence of emotional problems among infertile couples has been estimated to be around $25 \%-60 \%$. So the aim of our study was to determine emotional problems among a group of infertile women in Egypt.

Methods: A convenient sample of 300 women was recruited for the purpose of this study. The study was implemented at infertility unit and Out-patient gynaecologic section at El-Kasr El-Aini Hospital Cairo university - Egypt. Structured Selfadministered questionnaire was used for data collection consists of two parts: Part I which included participants socio-demographic characteristics. Part II: A developed profile of emotional problems was used to assess the emotional problems of the infertile women in terms of anxiety, phobia, obsession, psychosomatic symptoms, depression, and hysterical manifestations.

Results: Revealed that anxiety (83\%) was the most significant emotional problems among studied subjects, followed by depression (77\%), obsession (72\%), psychosomatic disorders (65\%), phobia (52\%), and hysterical manifestation (2\%). The levels of emotional problems had significant associated with subjects' age, level of education, duration of marriage and presence of children.

Conclusions: There are high prevalence of emotional problems among infertile women, the study yielded that causes of infertility were mainly related to female factors. Emotional problems of the studied subjects ranked descending; anxiety, depression, obsession, psychosomatic disorders, phobia, and hysterical manifestation. So, it seems that more serious attention is required from nurses, gynecologists, psychiatrists and psychologists for better treatment of these emotional problems. The use of supportive teaching program should be considered as part of the general therapeutic framework of infertility.
\end{abstract}

Key Words: Emotional problems, Infertility, Stressful life experience, Anxiety, Phobia, Obsession, Psychosomatic symptoms, Depression, Hysterical manifestations

\section{INTRODUCTION}

Society is primarily organized for the families with children and the argument for having children can be very persuasive. Undoubtedly almost all new husbands and wives look forward to have children, as the most gifts each can give to the other. It is possible that a woman may consider her home incomplete without children, because children may serve as a symbol of unity of the marriage, or perhaps as an expression of her love for her husband. So couple will be deeply disappointed to discover that they seem to be unable to have the babies that they want so much. ${ }^{[1]}$ Infertility represents a serious crisis for the infertile women. This crisis evokes many feelings; some are due to the distress feeling and despair regarding their infertility. Other negative feelings are

*Correspondence: Sahar M. Yakout; Email: szamzam@ksu.edu.sa; Address: College of Nursing, Alexandria University, Alexandria, Egypt. 
based upon the pressures of society which in turn put a great stress on parenthood. It is frequently a source of emotional trauma for couples, placing stress on their relationship and may be the causes of many psychosexual problems as well as marital problem. ${ }^{[2]}$

There are many biological causes of infertility, some which may be treated with medical interventions. In other cases, the cause is may be due to immunological or genetic causes. The prevalence of infertility varies widely, being low in developed countries and high in developing countries because there are limited resources for investigation and treatment available. It affects $13 \%$ to $15 \%$ of couples worldwide. In the United Kingdom, it is estimated that one in six couples would complaint of infertility. ${ }^{[3]}$

Generally, worldwide it is estimated that one in seven couples have problems in conceiving, with the incidence similar to most countries independent on the level of the country's development. For a woman to conceive, certain things must be happen: intercourse must take at time of ovulation; the systems that produce eggs and sperm have to be working at optimum levels; and her hormones must be balanced. ${ }^{[4]}$

Couples with primary infertility have never been able to be pregnant, while, on the other hand, secondary infertility is difficulty conceiving after already having one normal pregnancy. Infertility may be referred also to both the man and woman; may be infertile or sub-fertile, and the couple's infertility arises from the combination of those conditions. ${ }^{[5]}$ Unexplained infertility; in about $15 \%$ of cases the infertility investigation will show no abnormalities. In those cases abnormalities are likely to be present but not known by current methods. Possible problems that the egg is not released at the best time for fertilization that it may not suctioned by the fimbriae end of fallopian tube, sperm may not be able to fertilize the egg, fertilization may fail to occur, transport of the zygote may be disturbed, or implantation fails. It is increasingly recognized that egg quality is of critical importance and women of advanced maternal age have eggs of reduced capacity for normal and successful fertilization. ${ }^{[6]}$

The inability to conceive children is experienced as a stressful situation by individuals and couples all around the world. The consequences of infertility are manifold and may include societal repercussions and personal emotional suffering. ${ }^{[5]}$ They experienced greater dissatisfaction with themselves and their marriages. Females experienced greater discontent over time and had greater emotional problems than males because infertility had traditionally been viewed as a women problem and women have been expected to suffer greater emotional problems due to infertility. ${ }^{[7]}$ Infertile couples, known as non-communicators, were found to be affected even more by

Published by Sciedu Press infertility.

Previous studies showed that psychological symptoms like depression and anxiety among infertile females who were infertile is high. Mild depression symptoms have been reported in $12 \%$ to $54 \%$ of women during infertility treatments. In addition, $12 \%$ to $24 \%$ of them have been reported to suffer from anxiety problem. ${ }^{[8]}$

Anxiety is a case of mind which arise due to environmental stimulants that are perceived by the women as unpleasant and having threatening effects. Anxiety affect women's mood, expectations and motivation, and are the most mental disorders. ${ }^{[9]}$ During the infertility investigations and treatments, couples may feel intense anger. They may see that their life have treated them unfairly and their infertility is unjust. They may become intensely upset when they see other women achieve their pregnancy with no effort. They may feel very angry when they observe a pregnant woman displaying disgust or unhappiness with her pregnancy; when they see women with an unwanted or unplanned pregnancy seeking an abortion; or when they observe a mother or father abusing their children. ${ }^{[10]}$

\subsection{Significance of the study}

A woman that is trying to conceive will experience feelings of frustration and disappointment if a pregnancy is not easily achieved because there is a connection between mind-body and fertility. However, if the difficulties progress and the man and/or woman are labeled as having fertility problems, then this may result in a severe insult to self-esteem, body image, and self-assessed masculinity or femininity. ${ }^{[1]]}$ Infertility is not an absolute condition but it is a relative inability to be pregnant and many couples may conceive without treatment or by treatment. Fertility treatments, ranging from medical investigations, to hormonal treatment and in vitro fertilization (IVF), are both physical and emotional load on women and their husband. Emotional problems such as depression, state-anxiety, and stress-induced changes in heart rate and cortisol level are predictive of a decreased probability of achieving a viable pregnancy. ${ }^{[11,12]}$

Treatment of infertility had unwittingly led to a disregard for the emotional problems that couples had, which include distress, loss of control, stigmatization, and a disruption in the developmental trajectory of adulthood. There are evidence of arising an association between stress of fertility treatment and women drop-out and pregnancy rates. Fortunately, psychological interventions, especially those emphasizing stress during management and coping-skills training, have been shown to have beneficial effects for infertile women. ${ }^{[12]}$

Nurse specialized in management of those type of women 
should broaden her assessment and management to involve all aspect of care. Holistic approach should be included for the nurse to include psychosocial assessment and management. So, the aim of this study is to evaluate women psychological status rather the biological status. As many researchers cover the biological aspect of infertile women, the nurse researcher will identify the emotional problems of infertile women.

\subsection{Aim of the study}

This study aimed to assess emotional problems of infertile women in Egypt.

\subsection{Research questions}

- What is the common emotional problems of infertile women?

- Is there a relation between types of infertility and emotional problems?

- Are there an association between emotional problems and socio-demographic characteristics?

\section{SubJECTS AND METHOD}

\subsection{Study design}

Quantitative exploratory research design was used to explore the emotional problems of the study participants.

\subsection{Study setting}

This study was carried out at infertility unit and the Outpatient gynaecologic department at El-Kasr El-Aini HospitalCairo, Egypt.

\subsection{Subjects}

A convenience sample of 300 infertile women attending the previously mentioned setting during their seeking of their treatment.

\subsubsection{Criteria for inclusion}

- Fertility age not less than 20 years.

- Duration of marriage not less than 1 year.

- Has regular sexual intercourse without the functional use of contraceptive methods.

- Free from any other debilitating chronic illness.

\subsubsection{Exclusion criteria}

Women who have any previous psychological disease or treatment.

\subsection{Tool of data collection}

Structured interview questionnaire was developed in Arabic language by the researchers after reviewing the related literatures. It consists of two parts:
Part I: This part included questions related to sociodemographic characteristics of infertile women like age, level of education, occupation, age at marriage, duration of marriage, presence of children, monthly income, gravidity, parity, type of infertility and interval between marriage and treatment in infertile group. It also included history of infertility treatment, persons encouraging infertile females to seek infertility treatment.

Part II: In order to detect emotional problems, we developed profile of emotional problems to assess the emotional problems of the infertile women in terms of anxiety, phobia, obsession, psychosomatic symptoms, depression, and hysterical manifestations. The sheet included 48 items, divided equally over the 6 types of emotional problems i.e., each emotional problem had 8 items. The items assessing anxiety were based on a short version of Spielberger State and Trait Anxiety Inventory. ${ }^{[13,14]}$ The depression items were the 8 items of the short Beck Depression Inventory version. ${ }^{[15]}$

The items on phobia, obsession and hysterical manifestations were assessed using some items of the $\mathrm{BSI}^{[16]}$ and The profile of mood states has been widely used for measuring emotional problems. ${ }^{[17]}$ The validation study of the Japanese version of the POMS was reported by Yokoyama et al. (1990) $)^{[18]}$ and standardized with 5,557 normal controls, both male and female, between the ages of 10 and 60. ${ }^{[19]}$ The reliability and validity have been tested in past studies. ${ }^{[16]}$ Psychosomatic symptoms based on Chachamovic et al. (2007) ${ }^{[20]}$ who measure quality of life of women experience infertility.

Scoring of items: The sheet included 48 items, divided equally over the 6 types of emotional problems i.e., each emotional problem had 8 items, 2 grades were given to each item. The answers are in the form of "No", or "Sometimes" or "Yes". "No" takes zero grades, "sometimes" takes one grade, and "yes" takes two grades. The maximum score for each of emotional problem was 16 , the minimum being zero. Women who get scores from zero to eight were considered to be free from any developing specific emotional problem. Those who get score above 8 indicated a tendency toward developing the emotional problem. A total score of 3 levels of emotional problem was 96, from 0-32 means mild emotional problem; 33-63 means moderate emotional problem, 64-96 means severe emotional problem.

\subsection{Validity and reliability}

Content validity of the tool was ascertained by three experts in psychiatric and mental health nursing and three experts in maternal and child Health Nursing who revised the tool for clarity, relevance, applicability, comprehensiveness, and easiness for implementation and according modifications were

ISSN 1925-4040 E-ISSN 1925-4059 
applied. Tool was tested for reliability by Cronbach's alpha which measured 0.83 .

\subsection{Pilot study}

The pilot study was carried out on 30 women to assess content face validity, who were chosen from fertility unit and the Out-patient gynaecological department at gynaecological hospital, El-Kasr El-Aini Hospital-Cairo, Egypt. Specific effort was done to have the women in this pilot with the same criteria as those of the study. From this pilot study, it was found out that: sentences were clear, few words have been modified. Following this pilot study, the schedule was reconstructed and made ready for use.

\subsection{Procedure}

An official letter was issued from the Faculty of Nursing, Cairo University and forwarded to the manager of El-Kasr El-Aini Hospital order to obtain their approval to carry out the study. Once official permission was obtained from the responsible authorities, the aim and the nature of the study were explained to the subjects who fulfill the criteria and agree to share in the study and an oral consent was obtained. The psychiatric assessment was conducted by a trained professional in order to make an assessment for each patient to determine if they were prepared for the treatment, if they understand completely, and if they are mentally stable. Also, interview was preferred to develop a relationship with infertile females and give them an opportunity to talk about their fears, and their reactions to infertility. Also, the main reason for the interview was to overcome the problem of illiteracy among women and to facilitate them to understand the questions and to obtain the necessary data in relation to the general characteristics of studied subjects and to evaluate their feelings and their needs. It was found that the average interview was conducted in about 20 to 30 minutes. The study was conducted from the beginning of April 2015 to August 2015.

\subsection{Ethical consideration}

Informed consent was obtained from the subjects in the current study. Confidentiality of each participant was protected by allocation of the code instead of using subject's name. All participants in this study were informed about the aim of this study in order to obtain their acceptance to share in this study. All events that occurred during data collection were considered confidential.

\subsection{Statistical analysis}

The collected data were coded and analyzed using SPSS version 21. Emotional problems were examined for association with a variety of socio-demographic characteristics of the study subjects using Chi-square test with significance when $p<.05$.

\section{RESULTS}

Table 1 highlighted that (60\%) of the infertile females aged below 30 years and $(42 \%)$ of them had primary level of education. Most of the studied subjects were housewives (97\%). Almost two-third (65\%) of the total subjects was married below and at the age of twenty years. Regarding to duration of marriage, more than one third (39\%) of the total subjects were married for less than 5 years. In relation to presence of children with the infertile women, almost three-quarter (73\%) had no children. In relation to the types of infertility, the majority of the total subjects (73\%) had primary infertility and more than one half (52\%) stayed 2 years to seek medical intervention. As regard duration of infertility treatment, the majority of the total subjects (63\%) treated for more than up to 4 years.

Table 1. Distribution of the study subjects according to their socio-demographic characteristics $(n=300)$

\begin{tabular}{|c|c|c|}
\hline Variables & No. & $\%$ \\
\hline \multicolumn{3}{|l|}{ Age } \\
\hline$<30$ & 180 & 60.0 \\
\hline $30-40$ & 120 & 40.0 \\
\hline \multicolumn{3}{|l|}{ Level of education } \\
\hline Illiterate/can read or write & 114 & 38.0 \\
\hline Primary school & 126 & 42.0 \\
\hline Secondary school & 45 & 15.0 \\
\hline University level & 15 & 5.0 \\
\hline \multicolumn{3}{|l|}{ Occupation } \\
\hline Housewife & 291 & 97.0 \\
\hline Employed & 9 & 3.0 \\
\hline \multicolumn{3}{|l|}{ Age at marriage } \\
\hline$\leq 20$ years & 195 & 65.0 \\
\hline$>20$ years & 105 & 35.0 \\
\hline \multicolumn{3}{|l|}{ Duration of marriage } \\
\hline$<5$ years & 117 & 39.0 \\
\hline $5-10$ years & 90 & 30.0 \\
\hline$>10$ years & 93 & 31.0 \\
\hline \multicolumn{3}{|l|}{ Presence of children } \\
\hline No children & 219 & 73.0 \\
\hline Living children & 45 & 15.0 \\
\hline Dead children & 36 & 12.0 \\
\hline \multicolumn{3}{|l|}{ Gravidity } \\
\hline None & 219 & 73.0 \\
\hline Once & 81 & 27.0 \\
\hline \multicolumn{3}{|l|}{ Parity } \\
\hline None & 219 & 73.0 \\
\hline Once & 81 & 27.0 \\
\hline \multicolumn{3}{|l|}{ Types of Infertility } \\
\hline Primary & 219 & 73.0 \\
\hline Secondary & 81 & 27.0 \\
\hline \multicolumn{3}{|c|}{ Interval between marriage and treatment } \\
\hline $2-$ & 156 & 52.0 \\
\hline $3-$ & 105 & 35.0 \\
\hline$>4$ years & 39 & 13.0 \\
\hline \multicolumn{3}{|c|}{ Duration of infertility treatment } \\
\hline Up to 4 years & 111 & 63.0 \\
\hline More than 4 years & 189 & 37.0 \\
\hline
\end{tabular}


Table 2 showed that less than two-third of the total subjects $(60 \%)$ had female factor as a cause of infertility. The majority of the total subjects $(79 \%)$ had previous history of infertility treatment. As regard to the person who encourages infertile woman to seek infertility treatment, more than one-third of them encouraged by their neighbors $(39 \%)$ followed by their mothers $(27 \%)$.

Figure 1 illustrated that the majority of the subjects $(83 \%)$ had an anxiety disorders, followed by depression (77\%), then obsession $(72 \%)$, then psycho-somatic disorders $(65 \%)$, while more than half $(52 \%)$ had phobia. The minority of them $(2 \%)$ had hysteria.

In relation to emotional problems, as shown in Table 3, most of subjects $(89 \%)$ had obsession followed by anxiety (86.3\%) then psycho-somatic (64.4\%) among women who had primary infertility. The majority of the women who had secondary infertility $(88.9 \%)$ had depression followed by anxiety $(74.1 \%)$ then psycho-somatic $(66.7 \%)$. There is significant relationship in relation to obsession $(p=.001)$.

As regard to emotional problems, most of subjects $(88.9 \%$ $\& 86.5 \%$ ) had phobia among women who treated for more than and up to four years respectively, followed by obsession $(87.3 \%)$ and depression $(81 \%)$ then anxiety $(77.8 \%)$ and psycho-somatic disorders $(69.8 \%)$ among women who treated for more than four years respectively. In relation to women who treated only up to four years, the present emotional problems were psycho-somatic disorders $(78.4 \%)$, followed by anxiety $(67.6 \%)$ and depression $(54.1 \%)$ respectively. There is significant correlation in relation to obsession $(p \leq .001)($ see Table 4$)$

Table 2. Distribution of the study subjects according to their history of infertility

\begin{tabular}{lll}
\hline History & No. & \% \\
\hline Causes of infertility & & 60.0 \\
Female factor & 180 & 30.0 \\
Male and female factor & 90 & 10.0 \\
Unexplained infertility & 30 & 79.0 \\
History of infertility treatment & & 21.0 \\
Yes & 237 & 39.0 \\
No & 63 & 17.0 \\
Persons encouraging infertile females to seek infertility treatment & 15.0 \\
Neighbors & 117 & 27.0 \\
Patient herself & 51 & 2.0 \\
Husband & 45 & 81 \\
Mother & 6 & \\
Husband family & 8 & \\
\hline
\end{tabular}

Table 5 showed that $67 \%$ of the studied subjects had mild level of emotional problems while $7 \%$ had severe level of emotional problems.

Table 6 clarified that levels of emotional problems had significant correlation with subjects' age, level of education, duration of marriage and presence of children as $(p=.000 ; p$ $=.015 ; p=.002 ; p=.0032$ ) respectively. While, there were no significant correlation between emotional problems and occupation and also age at marriage.

Table 7 showed that study subjects' age was correlated with anxiety, obsession and psycho-somatic disorders. As regard correlation between level of education and emotional problems, it was found that level of education was correlated with psycho-somatic disorders. This Table reveals no correlation between subjects' occupation and any of the emotional problems. Subjects' age at marriage was correlated with anxiety, phobia and obsession. The results show that duration of marriage was correlated with phobia and obsession. The socio-demographic variable presence of children was found to be correlated with anxiety, phobia, obsession, psychosomatic disorders and depression.

\section{Discussion}

Infertility is a very stressful life experience where women may experience lack of self-confidence, feeling of resentment, threat, depression, anxiety, phobia, failure, marital problems and they believed that the above factors are related to infertility. Infertility imposes significant stress on these subjects. In 2010, there was an estimated 48.5 million infertile couples worldwide, and from 1990 to 2010 there was little change in levels of infertility in most of the world. In 2010, the countries with the lowest rates of female infertility included the South American countries. The highest rate regions included Eastern Europe, North Africa, The Middle East. $^{[21]}$ 


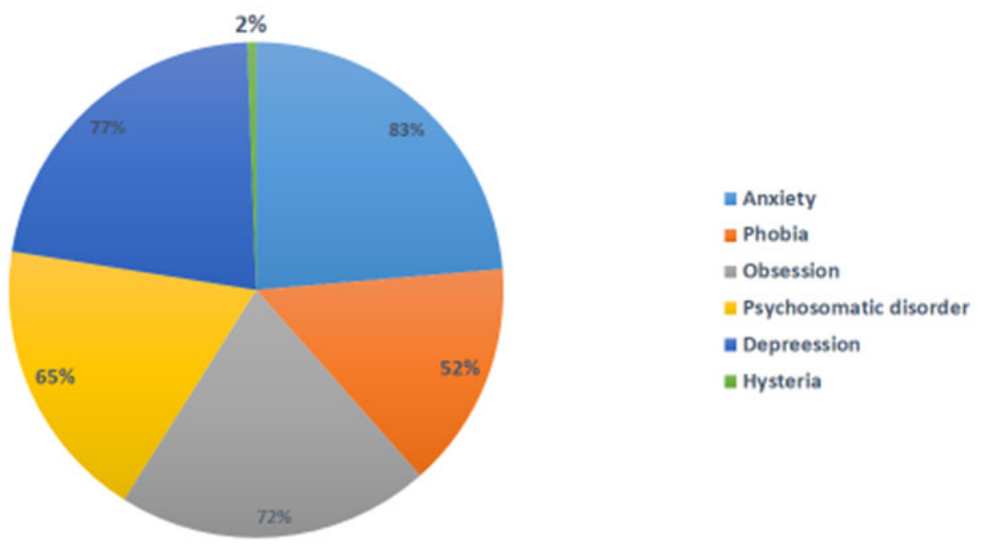

Figure 1. Emotional problems of infertile women

Table 3. Relationship between emotional problems and types of infertility (primary vs. secondary) $(n=300)$

\begin{tabular}{|c|c|c|c|c|c|}
\hline \multirow{2}{*}{ Emotional problems } & \multicolumn{2}{|c|}{ Primary $(n=219)$} & \multicolumn{2}{|c|}{ Secondary $(n=81)$} & \multirow{2}{*}{$p$-value } \\
\hline & No. & $\%$ & No. & $\%$ & \\
\hline Anxiety & 189 & 86.3 & 60 & 74.1 & .113 \\
\hline Phobia & 114 & 52.1 & 42 & 51.9 & .668 \\
\hline Obsession & 195 & 89.0 & 21 & 25.9 & $.001^{*}$ \\
\hline Psycho-somatic & 141 & 64.4 & 54 & 66.7 & .782 \\
\hline Depression & 156 & 71.2 & 72 & 88.9 & .107 \\
\hline Hysterical manifestation & 0 & 0.0 & 6 & 7.4 & - \\
\hline
\end{tabular}

Note. There was more than one answer for each parameter. *Significant level at $p<.05$.

Table 4. Relationship between emotional problems and duration of infertility treatment $(\mathrm{n}=300)$

\begin{tabular}{|c|c|c|c|c|c|}
\hline \multirow{2}{*}{$\begin{array}{l}\text { Emotional problems } \\
\text { Anxiety }\end{array}$} & \multicolumn{2}{|c|}{ Up to 4 years $(n=111)$} & \multicolumn{2}{|c|}{$>4$ years $(n=189)$} & \multirow{2}{*}{$\begin{array}{l}p \text {-value } \\
.255\end{array}$} \\
\hline & 75 & 67.6 & 147 & 77.8 & \\
\hline Phobia & 96 & 86.5 & 168 & 88.9 & .845 \\
\hline Obsession & 54 & 48.6 & 165 & 87.3 & $.001^{*}$ \\
\hline Psycho-somatic & 87 & 78.4 & 132 & 69.8 & .211 \\
\hline Depression & 60 & 54.1 & 153 & 81.0 & $.017^{*}$ \\
\hline Hysterical manifestation & 6 & 5.4 & 0 & 0.0 & - \\
\hline
\end{tabular}

*Significant level at $p<.05$.

Table 5. Distribution of the study subjects according to the three levels of emotional problems among infertile women $(\mathrm{n}=300)$

\begin{tabular}{lll}
\hline Level of emotional problems & Number & \% \\
\hline Mild & 201 & 67.0 \\
Moderate & 78 & 26.0 \\
Severe & 21 & 7.0 \\
Total & $\mathbf{3 0 0}$ & $\mathbf{1 0 0 . 0}$ \\
\hline
\end{tabular}

In this study, it was observed that $60 \%$ of infertile females' age was less than thirty and $63 \%$ of them up to 4 years seeking for medical treatment. This denotes that Egyptian females frequently seek medical treatment, when they are younger than thirty years. This is positive as in such age the response to treatment is more favorable. As Alhassan, et al. ${ }^{[22]}$ who reported that, A woman's best reproductive years are in her 20s. Fertility gradually decrease in the 30s, especially after age 35 . Each month that she tries, a healthy, fertile 30 -year-old woman has a $20 \%$ chance to be pregnant. That means that for every 100 fertile 30 -year-ont women trying to get pregnant in 1 cycle, 20 will be successful and the other 80 will fail. By age 40, a woman's chance is less than $5 \%$ per cycle, so fewer than 5 out of every 100 women are expected to be pregnant each month. 
This study also showed that most of studied subjects were housewives while minority was employed. This does not mean that, only women with such characteristics were infertile, but these are the characteristics of the majority of the participants. The desire of many young women to become mother may be influenced by the premium placed on chil- dren by society. In Africa, children are highly valued for social, cultural and economic reasons. Infertile and childless women in Africa are therefore confronted with a series of societal discrimination and stigmatization which may lead to emotional problems such as anxiety and depression. ${ }^{[22]}$

Table 6. Correlation between socio-demographic characteristics and levels of emotional problems among infertile women $(\mathrm{n}=300)$

\begin{tabular}{|c|c|c|c|c|c|}
\hline Socio-demographic characteristics & Mild & Moderate & Severe & Total & $p$-value \\
\hline \multicolumn{6}{|l|}{ Age } \\
\hline$<30$ & 156 & 18 & 6 & 180 & \multirow[t]{2}{*}{$.0001^{*}$} \\
\hline $30-40$ & 45 & 60 & 15 & 120 & \\
\hline \multicolumn{6}{|l|}{ Level of education } \\
\hline Illiterate/can read or write & 66 & 48 & 0 & 114 & \multirow{4}{*}{$.015^{*}$} \\
\hline Primary school & 111 & 15 & 0 & 126 & \\
\hline Secondary school & 24 & 15 & 6 & 45 & \\
\hline University level & 0 & 0 & 15 & 15 & \\
\hline \multicolumn{6}{|l|}{ Occupation } \\
\hline Housewife & 198 & 72 & 21 & 291 & \multirow[t]{2}{*}{.25} \\
\hline Employed & 3 & 6 & 0 & 9 & \\
\hline \multicolumn{6}{|l|}{ Age at marriage } \\
\hline$\leq 20$ yrs & 132 & 57 & 6 & 195 & \multirow[t]{2}{*}{.088} \\
\hline$>20 \mathrm{yrs}$ & 69 & 21 & 15 & 105 & \\
\hline \multicolumn{6}{|l|}{ Duration of marriage } \\
\hline$<5 \mathrm{yrs}$ & 105 & 12 & 0 & 117 & \multirow{3}{*}{$.0021 *$} \\
\hline $5-10$ yrs. & 75 & 15 & 0 & 90 & \\
\hline$>10 \mathrm{yrs}$ & 21 & 51 & 21 & 93 & \\
\hline Presence of children & 0 & & & & \multirow{5}{*}{$.0032 *$} \\
\hline No children & 126 & 72 & 21 & 219 & \\
\hline Living children & 45 & 0 & 0 & 45 & \\
\hline Dead children & 30 & 6 & 0 & 36 & \\
\hline Total & 201 & 78 & 21 & 300 & \\
\hline
\end{tabular}

*Significance level at $p<.05$.

The study reveals that $73 \%$ of the study infertile women were childless; this is consistent with Dyer et al. ${ }^{[23]}$ who stated that, the stigma of childlessness is so great that infertile women are socially isolated and neglected. Also, Alhassan et al. ${ }^{[22]}$ stated that infertile women are often excluded from social occasion and ceremonies or may even be deprived and perceived as inauspicious. Available evidence suggests that the social and psychological complications of infertility are particularly profound for African women as compared to men as reported by Arthur et al. ${ }^{[24]}$ This is well observed in this study where $52 \%$ of the infertile group required medical advice within the first two years of their marriage; this reflects the importance of having children among Egyptian females.

In relation to the Persons who encourage infertile females to seek infertility treatment and the amount of pressure of society on the women to bear children, this study demonstrated that $39 \%, 27 \%$ and $2 \%$ of the infertile women were encouraged to seek medical treatment by their neighbors, their mothers and then at last husband family. In accordance studies done in Egypt and some countries in Africa. Because people on authority put pressure on infertile female to seek medical advice because having children continue the family and increase marital satisfaction. Childless women therefore stand at risk of stigmatization especially from relatives of 
husband and may even lead to a divorce or another wife be- Ramezanzadeh et al. ${ }^{[25]}$ clarified that in Islamic and eastern ing brought into the marriage as permitted by Islamic law. countries such as Iran, family status especially childbearing is very important and valuable.

Table 7. correlation between socio-demographic characteristics and emotional problems among infertile women $(\mathrm{n}=300)$

\begin{tabular}{|c|c|c|c|c|c|c|c|c|c|c|c|c|}
\hline \multirow{2}{*}{$\begin{array}{l}\text { Socio-demographic } \\
\text { characteristics }\end{array}$} & \multicolumn{2}{|c|}{ Anxiety } & \multicolumn{2}{|c|}{ Phobia } & \multicolumn{2}{|c|}{ Obsession } & \multicolumn{2}{|c|}{$\begin{array}{l}\text { Psycho-somatic } \\
\text { disorders }\end{array}$} & \multicolumn{2}{|c|}{ Depression } & \multicolumn{2}{|c|}{$\begin{array}{l}\text { Hysterical } \\
\text { manifestation }\end{array}$} \\
\hline & No. & $\%$ & No. & $\%$ & No. & $\%$ & No. & $\%$ & No. & $\%$ & No. & $\%$ \\
\hline Age & & & & & & & & & & & 3 & 1.0 \\
\hline$<30$ & 135 & 75.0 & 96 & 53.3 & 114 & 63.3 & 135 & 75.0 & 126 & 70.0 & 3 & 1.0 \\
\hline $30-40$ & 114 & 95.0 & 60 & 50.0 & 102 & 85.0 & 60 & 50.0 & 105 & 87.5 & & \\
\hline$p$-value & $.012 *$ & & $>.05$ & & $.025^{*}$ & & $.044 *$ & & $>.05$ & & & \\
\hline \multicolumn{13}{|l|}{ Level of education } \\
\hline Illiterate/can read or write & 90 & 78.9 & 60 & 52.6 & 84 & 73.7 & 66 & 57.9 & 75 & 65.8 & 6 & 2.0 \\
\hline Primary school & 114 & 90.5 & 72 & 57.1 & 108 & 85.7 & 108 & 85.7 & 114 & 90.5 & 0 & 0.0 \\
\hline Secondary school & 36 & 80.0 & 18 & 40.0 & 15 & 33.3 & 15 & 33.3 & 30 & 66.7 & 0 & 0.0 \\
\hline University level & 9 & 60.0 & 6 & 40.0 & 9 & 60.0 & 6 & 40.0 & 12 & 80.0 & 0 & 0.0 \\
\hline$p$-value & $>.05$ & & $>.05$ & & $>.05$ & & $.012 *$ & & $>.05$ & & & \\
\hline \multicolumn{13}{|l|}{ Occupation } \\
\hline Housewife & 246 & 84.5 & 153 & 52.6 & 210 & 72.2 & 192 & 66.0 & 231 & 79.4 & 6 & 2.0 \\
\hline Employed & 3 & 33.3 & 3 & 33.3 & 6 & 66.7 & 3 & 33.3 & 0 & 0.0 & 0 & 0.0 \\
\hline$p$-value & $>.05$ & & $>.05$ & & $>.05$ & & $>.05$ & & - & & & \\
\hline \multicolumn{13}{|l|}{ Age at marriage } \\
\hline$\leq 20 \mathrm{yrs}$ & 180 & 92.3 & 126 & 64.6 & 174 & 89.2 & 138 & 70.8 & 144 & 73.8 & 3 & 1.0 \\
\hline$>20$ yrs. & 69 & 65.7 & 30 & 28.6 & 42 & 40.0 & 57 & 54.3 & 87 & 82.9 & 3 & 1.0 \\
\hline$p$-value & $.031^{*}$ & & $.022 *$ & & $.013^{*}$ & & $>.05$ & & $>.05$ & & & \\
\hline \multicolumn{13}{|l|}{ Duration of marriage } \\
\hline$<5$ yrs. & 96 & 82.1 & 75 & 64.1 & 96 & 82.1 & 78 & 66.7 & 87 & 74.4 & 3 & 1.0 \\
\hline $5-10$ yrs. & 78 & 86.7 & 57 & 63.3 & 75 & 83.3 & 66 & 73.3 & 72 & 80.0 & 3 & 1.0 \\
\hline$>10 \mathrm{yrs}$ & 75 & 80.6 & 24 & 25.8 & 45 & 48.4 & 51 & 54.8 & 72 & 77.4 & 0 & 0.0 \\
\hline$p$-value & $>.05$ & & $.014 *$ & & $.002 *$ & & $>.05$ & & $>.05$ & & & \\
\hline \multicolumn{13}{|l|}{ Presence of children } \\
\hline No children & 210 & 95.9 & 150 & 68.5 & 186 & 84.9 & 174 & 79.5 & 204 & 93.2 & 6 & 2.0 \\
\hline Living children & 9 & 20.0 & 0 & 0.0 & 15 & 33.3 & 15 & 33.3 & 15 & 33.3 & 0 & 0.0 \\
\hline Dead children & 30 & 83.3 & 6 & 16.7 & 15 & 41.7 & 6 & 16.7 & 12 & 33.3 & 0 & 0.0 \\
\hline$p$-value & $.001 *$ & & $.001 *$ & & $.016^{*}$ & & $.017 *$ & & $.002 *$ & & & \\
\hline
\end{tabular}

* Significance level at $p<.05$.

In Egyptian culture, negative attitude toward infertility are so miserable. Having a child is psychologically a vital role for women, and the absence of children may lead to marital problems. Husband's family, attitude and behavior of surroundings (family, friends, neighbors, etc.) causes psychological problems for infertile women. Generally infertile women experience negative social consequences including marital instability, stigmatization and abuse. Infertility can have a serious effect on both psychological well-being and social status of women in our country. ${ }^{[26]}$

Published by Sciedu Press
The current study showed that the majority of the total subjects of infertile women had primary infertility while, the minority had secondary infertility. As regard to the personality traits, majority (89\%) of primary infertile female had obsession followed by anxiety $(86.3 \%)$ then $(64.4 \%)$ psycho-somatic symptoms. The majority of the women who had secondary infertility had depression followed by anxiety then psycho-somatic. This result is in contradiction with Alhassan et al. ${ }^{[22]}$ who declared that the type of infertility presented by the women and previous conception both had 
significant effect on the level of depression, with women presenting with primary infertility tending to be more depressed. We added that in primary infertility the woman has not been able to have a live birth putting into question her womanhood. This is seemingly loss of identity as a woman is enough grounds to divorce in society and can thus be a solid ground for serious emotional problems.

As regard to emotional problems, $86.5 \%$ and $88.9 \%$ of women who treated for more than and up to four years had phobia respectively. Obsession $87.2 \%$, depression $81 \%$, anxiety $77.8 \%$ and psycho-somatic disorders $69.8 \%$ among women who treated for more than four years respectively. In relation to women who treated only up to four years, the present emotional problems were psycho-somatic disorders, followed by anxiety and depression respectively. This is consistent with Burns, ${ }^{[27]}$ who stated that the psychological consequences of prolonged infertility treatment lead to high level of distress, self report physical complaints. Furthermore, treatment failure was associated losses of fertility, self-esteem and social status are the same for both strategies, the latter finding suggests that the distress women experience due to IVF treatment failure not only results from the threat of infertility, but also from IVF treatment itself. The latter finding suggests that the distress women experience due to IVF treatment failure not only results from the threat of infertility, but also from IVF treatment itself. According to the cognitive dissonance theory, people will value their goal more if it is harder to reach. In line with this theory, one could hypothesize that these people are more likely to experience higher distress when this goal cannot be reached than people who invested less in the achievement of the same goal. The fact that women who underwent the standard IVF strategy were more distressed at treatment failure, might suggest that overall, standard IVF was related to more treatment-related discomfort. ${ }^{[27,28]}$

Actually a person with a certain emotional problems tend to use different mechanisms to cope with stress, which differs according to her type of personality. So, anxious infertile female had uncomfortable feeling about herself and her body. She will loose her identity, she had impaired attention, her high anxiety level changed her relationship with her husband, family and friend, and if she can not cope with her situation she developed a morbid state in the form of anxiety neurosis.

It was found that the infertile females whose with duration of marriage was less than 4 years had higher levels of phobia, obsession, and psychosomatic disturbance than those with duration of marriage were more than 4 years. This may be attributed to the fact that younger infertile women who are expected to be newly married suffer from a high stress of parents and surrounding to have children

With discussion of the study subjects, it seems that, Infertility raises several fears in women. Fears associated with body dysfunction, concern over sexual desirability, interpersonal and sexual relation, and fear about dangers to her marriage. So, with continuous fear the infertile females will develop phobic neurosis, and will have an intense fear from particular groups of people which in. turn she will avoid to be in contact with them.

Stress, depression and anxiety are described as common complications of infertility. A number of studies have found that the incidence of depression in infertile couples presenting for infertility treatment is significantly higher than in fertile controls, with prevalence estimates of major depression in the range of $15 \%-54 \% .{ }^{[29]}$ Anxiety has also been shown to be significantly higher in infertile couples when compared to the general population, with $8 \%-28 \%$ of infertile couples reporting clinically significant anxiety. ${ }^{[30]}$

In the present study, it is quite apparent that the scores obtained by infertile females were significantly higher (anxiety $83 \%$, phobia $52 \%$, obsession $72 \%$, psychosomatic $65 \%$, depression $77 \%$ ). Because infertility is not only a medical and social problem but also a psychological one, various studies on infertility indicated that infertile women are more likely to have psychiatric pathology and typical emotional problems that resulted from their inability to conceive. ${ }^{[5]}$

On the other hand, it was found that infertile women aged 30 years or more tended to get higher scores in anxiety $95 \%$, depression $87.5 \%$ and obsession $85 \%$. This is expected because older women have limited chance to get children than younger ones, and this can lead to the observed depression. This was similar to other studies done in the same field that depression is more common in person experienced feeling of loss and observing the aging process in one self. This result is supported by Alhassan et al. ${ }^{[22]}$ who stated that the prevalence of depression among the infertile women is high, especially among infertile women aged 25 and above, those who are primary educated, those with not conceive before, as well as those who have been diagnosed as infertile for more than 3 years.

In this study it was also noticed that the occupation and education seemed to affect the emotional problems. So, the low level of education and housewives infertile females had higher levels of anxiety, obsession and psychosomatic complaints as compared to the employed and the better educated infertile women. This may be attributed to the fact that illiterates and housewives usually have limited access to sources of information and explanations about infertility and its con- 
sequences. Also, due to the long stay alone in the house, there is a feeling of lack of control in such unusual stressful situation. On the other hand, the working infertile females are able to express their thoughts and to discuss with her colleagues at work, their physical as well as their psychological problems pertaining to this situation. At the same time, they can accept and adjust with these stressful events. Working women also have derived satisfaction and develop self esteem from their work. This can minimize the trauma of not having children.

Actually the results of our study help nurses to understand the emotional problems of the infertile females, but they should consider the special characteristics that predisposes to each of the traits. This will enable them to provide individualized care for their clients and thus to minimize the suffering of these unlucky clients. Minimizing the suffering and helping women to adjust may be a factor that contribute to the treatment of infertility.

\section{CONCLUSION AND RECOMMENDATIONS}

\subsection{Conclusion}

The study yielded that causes of infertility were mainly related to female factors. Emotional problems of the studied subjects ranked descending: anxiety, depression, obsession, psychosomatic disorders, phobia, and hysterical manifestation. It proved that, there is a significant correlation between emotional problems and subject age, level of education, du- ration of marriage and presence of children.

\subsection{Recommendations}

- Nurses should apply their management from biopsychosocial perspectives.

- Infertile women should be managed through health team to involve all aspects of care.

- Educational programs are necessary to upgrade the level of knowledge and the attitudes of Egyptian citizens in relationship to infertility and its social complications.

- The social media should educate people about infertility so that there is less pressure on infertile couples. It should make family members of infertile women have knowledge of the help and support they can give in order to decrease social stress.

- The findings indicated the necessary referral and intervention for psychological health for the infertile couples: Counseling methods, especially supportive psychotherapy, should be considered for infertile women.

- Further research is needed to understand the association between distress and fertility outcome, as well as effective psychosocial interventions.

\section{CONFLICTS OF INTEREST DISCLOSURE}

The authors declared no potential conflicts of interest with respect to the research, authorship, and/or publication of this article.

\section{REFERENCES}

[1] Pasha H, Faramarzi M, Salmalian H. Comparison of pharmacological and nonpharmacological treatment strategies in promotion of infertility self-efficacy scale in infertile women: A randomized controlled trial. Iran J Reprod Med Jun. 2013; 11(6): 495-502. PMid:24639784

[2] Mostafa A, Abolfotouh A, Alabdrabalnabi R, et al. Knowledge, attitude, and practices of infertility among Saudi couples. Int J Gen Med. 2013; 6: 563-573.

[3] Hamadaa A, Estevesb SC, Agarwala A. Unexplained male infertility: potential causes and management. Human Andrology. 2011; 1: 26. http://dx.doi.org/10.1097/01.XHA.0000397686.82729 .09

[4] Department of Health (United Kingdom). About infertility \& fertility problems from the Human Fertilisation and Embryology Authority. 2009.

[5] Poddar S, Sanyal N, Mukherjee U. Psychological profile of women with infertility: A comparative study. Industrial Psychiatry J. 2014; 23(2): 117-126. PMid:25788801 http://dx.doi.org/10.4103 10972-6748.151682

[6] Cousineau TM, Domar AD. Psychological impact of infertility. Best Practice \& Research. Clinical Obstetrics \& Gynecology. 2007; 21(2): 293-308. PMid:17241818 http://dx.doi.org/10.1016/j.bpo bgyn.2006.12.003

[7] Karaca A, Unsal G. Psychosocial Problems and Coping Strategies among Turkish. Women with Infertility. Asian Nursing Research.
2015; 9(3): 243-250. PMid:26412629 http://dx.doi.org/10. $1016 / j$. anr.2015.04.007

[8] Volgsten H, Shoog S, Ekselius L, et al. Prevalence of psychiatric disorders in infertile women and men undergoing in vitro fertilization. Hum Reprod. 2008; 23: 2056-2063. PMid:18583334 http://dx.doi.org/10.1093/humrep/den154

[9] Elder R, Evans K, Nizette D. Psychiatric and mental health nursing. 2nd ed. Sydney: Elsevier; 2009.

[10] Klock S. Psychological Issues Related to fertility. The Global Library of Women's Medicine. 2011.

[11] Cwikel J, Gidron Y, Sheiner E. Psychological interactions with infertility among women. European Journal of Obstetrics \& Gynecology and Reproductive Biology. 2004; 117(2): 126-131. PMid:15541845 http://dx.doi.org/10.1016/j.ejogrb.2004.05.004

[12] Isaksson R, Tiitinen A. Present concept of unexplained infertility Gynecol Endocrinol. 2004 May; 18(5): 278-90. PMid:15346664 http://dx.doi.org/10.1080/0951359042000199878

[13] Spielberger CD. Manual for the State-trait Anxiety Scale. Palo Alto: Consulting Psychologists Press; 1983.

[14] Van der Ploeg HM, Defares PB, Spielberger CD. Handleiding bij de Zelfbeoordelingsvragenlijst: een Nederlandse bewerking van de Spielberger State Trait Anxiety Inventory. [Dutch manual for the Spielberger state and trait anxiety inventory]. Swets \& Zeitlinger: Lisse; 2000. 
[15] Beck AT, Guth D, Steer RA, et al. Screening for major depression disorders in medical inpatients with the Beck Depression Inventory for primary care. Behav Res Ther. 1997; 35: 785-791. http://dx.doi.org/10.1016/S0005-7967 (97)00025-9

[16] Derogatis LR, Melisaratos N. The Brief Symptom Inventory: an introductory report. Psychol Med. 1983; 13: 595-605. PMid:6622612 http://dx.doi.org/10.1017/S0033291700048017

[17] McNair DM, Lorr M, Droppleman LF. Manual for the Profile of Mood States. Educational and Industrial Testing Service, San Diego. 1971.

[18] Yokoyama K, Araki S, Kawakami N, et al. Production of the Japanese edition of profile of mood states (POMS): assessment of reliability and validity. Koushueiseigaku Zasshi (Jpn. J. Epidemiol.). 1990; 37 913-918.

[19] Yokoyama K, Araki S. Japanese edition of profile of mood states (POMS). Kaneko Shobou (in Japanese). 1994.

[20] Chachamovich JR, Chachamovich E, Zachia S, et al. What variables predict generic and health-related quality of life in a sample of Brazilian women experiencing infertility? Hum Reprod. 2007; 22(7): 1946-52. PMid:17428881 http://dx.doi.org/10.1093/humre $\mathrm{p} / \mathrm{dem} 080$

[21] American Society for Reproductive Medicine. 1209 Montgomery Highway, Birmingham, AL. 2012.

[22] Alhassan GA, Ziblim A, Muntaka S. A survey on depression among infertile women in Ghana. BMC Women's Health. 2014; 14: 42. PMid:24612693 http://dx . doi .org/10.1186/1472-6 874-14-42

[23] Dyer SJ, Abrahams N, Mokoena NE, et al. Psychological distress among women suffering from couple infertility in South Africa: A quantitative assessment. Hum Reprod. 2005; 20(7): 1938-
1943. PMid:15774542 http://dx.doi.org/10.1093/humrep/ deh845

[24] Greil AL, Slauson-Blevins K, McQuillan J. The experience of infertility: A review of recent literature. Sociol Health Illn. 2010 Jan; 32(1): 140-162. PMid:20003036 http://dx.doi.org/10.1111 /j.1467-9566.2009.01213.x

[25] Ramezanzadeh F, Aghssa MM, Abedinia N, et al. A survey of relationship between anxiety, depression and duration of infertility. BMC Women's Health. 2004. PMid:15530170 http://dx.doi .org/10. 1186/1472-6874-4-9

[26] Abu-Rabia A. Infertility and Surrogacy in Islamic Society: SocioCultural, Psychological, Ethical, and Religious Dilemmas. The Open Psychology Journal. 2013; 6: 54-60. http://dx.doi .org/10.21 74/1874350101306010054

[27] Burns LH. Psychiatric Aspects of Infertility and Infertility Treatments. Psychiatric Clinics of North America. 2007; 30(4): 689716. PMid:17938041 http://dx.doi.org/10.1016/j.psc. 200 7.08 .001

[28] Cousineau TM, et al. Psychological Impact of Infertility, Best Practice \& Research. Clinical Obstetrics and Gynaecology. 2007; 21(2): 293-308. PMid:17241818 http://dx.doi.org/10.1016/j.bpo bgyn. 2006.12.003

[29] Chen TH, Chang SP, Tsai CF, et al. Prevalence of depressive and anxiety disorders in an assisted reproductive technique clinic. Hum Reprod. 2004; 19: 2313-18. PMid:15242992 http://dx.doi.org /10.1093/humrep/deh414

[30] Anderson KM, Sharpe M, Rattray A, et al. Distress and concerns in couples referred to a specialist infertility clinic. Journal of Psychosomatic Research. 2003; 54(4): 353-5. http://dx.doi.org/10.10 16/S0022-3999(02)00398-7 